\title{
Noah and Joseph Effects in Government Budgets: Analyzing Long-Term Memory
}

\author{
Bryan D. Jones and Christian Breunig
}

This article examines the combined effects of what mathematician Benoit Mandelbrot has termed
"Noah" and "Joseph" effects in U.S. national government budgeting. Noah effects, which reference the
biblical great flood, are large changes or punctuations, far larger than could be expected given the
Gaussian or Normal models that social scientists typically employ. Joseph effects refer to the seven fat
and seven lean years that Joseph predicted to the Pharaoh. They are "near cycles" or "runs" in time
series that look cyclical, but are not, because they do not occur on a regular, predictable basis. The Joseph
effect is long-term memory in time series. Public expenditures in the United States from 1800 to 2004
shows clear Noah and Joseph effects. For the whole budget, these effects are strong prior to World War
II (WWII) and weaker afterward. For individual programs, however, both effects are clearly detectable
after WWII. Before WWII, budgeting was neither incremental nor well behaved because punctuations
were even more severe and memory was not characterized by simple autoregressive properties. The
obvious break that occurred after WWII could have signaled a regime shift in how policy was made in
America, but even the more stable modern world is far more uncertain than the traditional incremental
view.

\section{Noah and Joseph in Government Budgets: Path Dependence or Long-Term Memory?}

In the broadest sense, path dependence implies that "history matters." At one level, this seems obvious, but at another, it is anything but obvious. Many analysts, quantitative and qualitative, implicitly assume a limited role for history in choosing cases for study or in the assumptions they make about data.

But how does history matter? Political scientists have used path dependence in many of the ways that history can matter in current affairs, from an "irreversible branching process" to just high costs of reversing courses (Levi, 1997). Pierson (2004) uses the concept to imply positive feedback, or increasing returns, in which each increment of change generates a larger increment of change, which is consistent with the original development of the term by economist Brian Arthur (1994).

Pierson (2004) has suggested that path dependence has suffered from "concept stretching," and Page (2006) details the various ways in which the concept has been

\section{MPIfG J ournal Article}

Bryan D. Jones, Christian Breunig: Noah and Joseph Effects in Government Budgets: Analyzing Long-Term Memory. In: Policy Studies Journal, 35(3), 329-348. (2007). Blackwell Publishing

The original publication is available at the publisher's web site: http://dx.doi.org/ 10.1111/j.1541-0072.2007.00227.x

The MPIfG Journal Articles series features articles by MPIfG researchers and visiting scholars published in peer-reviewed journals. Max Planck Institute for the Study of Societies (MPIfG) Cologne | www.mpifg.de 
used, suggesting that the concept is "almost metaphorical." A concept too "stretched" is not useful in analysis.

One possibility is to begin to calve off parts of the concept that are more amenable to rigorous analysis, distinguishing these parts from the broader "history matters" notion. The notion of "long-term memory" better captures many of the implicit meanings of path dependence and it has the advantage of clarifying just how positive feedback effects might operate. In this article, we explicate the notion that "history matters" using U.S. expenditure data from 1800 to 2004 to examine how long-term memory (and especially memory of dramatic, extreme events) has affected government budgeting.

There are two important advantages in the concept of long-term memory. First, the positive feedback effects that Arthur (1994) and Pierson (2004) claim characterize path dependence cannot exist for long in any system of limited capacity (as all political systems are). Increases in the rate of return either at some point are damped down or they will destroy the system. The classic example is the Richardson arms race model (Richardson, 1960). Lock-in may imply some sort of punctuated equilibrium in which at some point institutions forge stability that involves negative, not positive, feedback (Baumgartner \& Jones, 1993). Therefore, there is something awry with the concept as employed in political science. Long-term memory formulates the problem in a manner that avoids this trap.

Second, long-term memory can be systematically assessed, and the relative roles of history and simultaneous or near-simultaneous events as causes can be adduced. In the words of Benoit Mandelbrot, the mathematician who first recognized the theoretical importance of long-term memory in economic time series, these series possessed "long-range dependence in an otherwise random process-or put another way, a long-term memory through which the past continues the random fluctuations of the present" (Mandelbrot \& Hudson, 2004, p. 201). Here, Mandelbrot is not implying the lack of simultaneous causes; he means that even taking these into account, long-range dependence still exists.

How "path dependent" are public policies? Today's policies are a product of past legislation and present forces pressing adjustment, so the entire area is ripe for exploration from the point of view of how history and contemporaneous affairs interact. Moreover, government budgets are quantitative traces of policy activities - not the only ones, but important ones. This article analyzes the trace of public expenditures at the national level of government in the United States since 1800, primarily using outlays (actual expenditures) but supplementing the analysis with post-World War II (WWII) data on budget authority (expenses authorized by Congress that later are converted into outlays by executive agencies).

\section{Noah and Joseph Effects}

Mandelbrot has pointed to two processes in time series that indicate "wild randomness," which he terms the Noah and Joseph effects. Noah effects, which reference the biblical great flood, are large changes or punctuations, far larger than could be expected given the Gaussian or Normal models that social scientists 
typically employ. Joseph effects refer to the seven fat and seven lean years that Joseph predicted to the Pharaoh. They are "near cycles" or periods of large or small changes in the data that look cyclical, but are not, because they do not occur on a regular, predictable basis. A time series can contain effects either or both of them, and when both occur, they may or may not occur at the same time.

What Mandelbrot terms the Joseph effect is long-term memory in time series. Any effect in the past can affect the future through "memory" of the event. The data contain traces of the earlier event, as history matters. "The signals fade in time. But it can take months, years, or decades for a signal to become unremarkable. Such is long-term dependence. ... Every event, no matter how remote or long ago, echoes across all other events." (Mandelbrot \& Hudson, 2004, p. 229).

Noah effects are extreme values. In any time series, such extreme values will push the overall level of the series up or down in a dramatic fashion, even if they are rare. In the past, the prevailing view of such extreme events treated them as "outliers" because they fell so far outside of the bounds of prediction for normal Gaussian statistics. This has proved unsatisfactory both for practical problems (such as estimating catastrophic losses for insurance purposes) and for natural science. The occurrence of such extreme but very rare events in natural systems has spawned a new field of statistics, extreme value theory (Kotz \& Nadarajah, 2000; Malevergne \& Sornette, 2006; Sornette, 2006). The approach focuses on both studying full frequency distributions through stochastic process methods and developing estimators for the extreme values. This is preferred to the traditional approach of studying only the moments of distributions (generally only the mean and variance or standard deviation) and estimating parameters based on averages (such as regression coefficients).

Mandelbrot's insistence on taking extreme values seriously began as an exercise in the study of variations in cotton prices (Mandelbrot, 1967), which was a direct attack on what was termed the Efficient Market Thesis or EMT (for a review, see Cootner, 1964). The EMT claimed that, over time, stock market prices approximated a random walk because a fully efficient market would discount information such that "information contained in past prices is instantly, fully and perpetually reflected in the asset's current price" (Campbell, Lo, \& MacKinlay, 1997, p. 30). This formulation implies that the sum of period-to-period change in prices in a single stock or commodity, or in an index, will be Gaussian or Normal. Mandelbrot's classic article and much subsequent work showed that these prices were not so distributed and, hence, that the EMT was wrong.

This work has spawned a huge volume of work on the behavior of prices (Sornette, 2003) and has generated a new field of study, termed econophysics (Mantegna \& Stanley, 2000), directed at incorporating extreme events and long-term memory into the study of economic systems. Today this is leading to a rethinking of many of the fundamentals of classical economics (Beinhocker, 2006; Mirowski, 1990) in a manner that incorporates these assumptions into a new, less deterministic understanding of the field.

These fundamentals were brought to the study of public policy by Jones, Baumgartner, and True (Jones \& Baumgartner, 2005a; True, Jones, \& Baumgartner, 2007) in their work on public budgets. They show the importance of extreme values 
in budget behavior, hence undermining the classic understanding of budgets as solely incremental. By relying on distributional methods of univariate data, they argue that governing institutions shape budgetary outcomes depending on their capacity to process information and prioritize problems.

This article extends the stochastic process approach used by Jones and his colleagues to time series analysis. Noah and Joseph effects in budgets result in highly leptokurtic budget change distributions. However, lots more can be learned from detailed study of budget series by not collapsing the time series into a frequency distribution but rather by studying Noah and Joseph effects separately.

We want to convey that these issues are not fundamentally technical, and hence, analysts should not rush into estimation techniques, so we will employ an expository framework, adding rigor to the analysis as we go. History matters, and events (Noah effects) reverberate through time because of long-term memory (Joseph effects). The reason for beginning with path dependence is to convey our conviction that we are not engaged in a technical exercise in time series analysis but in a substantive historical adventure in understanding how to make sense of how past events and present pressures combine to produce today's public policies. Richard Rose and Philip Davies (1994) asked the right question more than a decade ago, broadening the notion of budget incrementalism into a query about historical influences in current policymaking, and this article is properly viewed as an extension of their well-crafted work.

We start with a picture of the time series we will study. Figure 1 depicts the real annual outlays for the U.S. government, plotted separately for defense and domestic

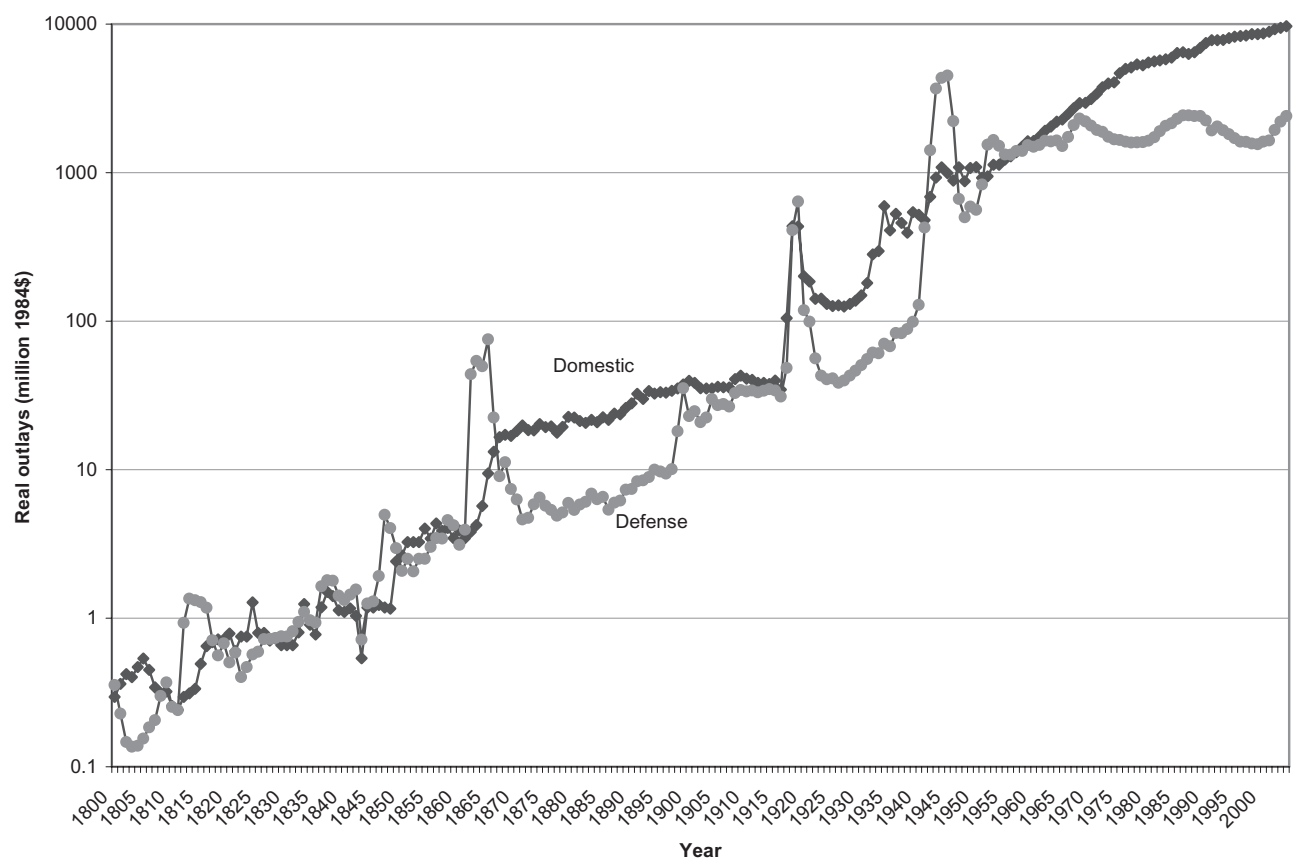

Figure 1. Real U.S. Outlays for Domestic and Defense Programs, 1800-2004. 
programs, adjusted for inflation and plotted on a logarithmic scale because of the vast changes in the size of government over the period. ${ }^{1}$ Two things seem evident from the graph. First, both series are characterized by periods of rapid, episodic, punctuated change (Noah effects). While it seems at first glance that budgets have been substantially less volatile since World War II than in the past, this period may simply be one of the periodic lulls that have characterized U.S. budgets throughout history. Or it could represent better budgeting techniques, but we would be foolhardy to assume the latter given the long-range pattern of the series. Second, while defense programs are more volatile before World War II, domestic programs have also been subject to rapid shifts. We turn now to a more exacting analysis. ${ }^{2}$

\section{Detecting Noah Effects}

A quick indication of the existence of large-scale punctuations in a set of measures is simply to plot them against time. Figure 2a plots the real (i.e., inflationadjusted) annual logarithmic rate of return for U.S. total budgetary outlays for domestic (nondefense) programs from 1800 to 2004. ${ }^{3}$ The plot includes error bars drawn around the time trend at $+/-$ three standard deviations. If the distribution of observations varied according to the typical Gaussian or normal curve assumptions, 99.73 percent of the observations should fall within the bars, and only 0.27 percent would be more extreme. We would predict, then, that $0.0027 \times 204=0.55$ or less than one observation in our budgetary series would exceed three standard deviations up or down from the average logarithmic return of 0.051 . In fact, seven observations do so, indicating that the standard Gaussian assumptions have gone terribly wrong. ${ }^{4}$

Note that the extreme values are associated with major disruptions, including war (the Mexican-American War and World War I, but neither the Civil War nor World War II). Recall that these are domestic expenditures, not directly defense related, indicating that some endogenous processes drive these changes; they are not a simple reaction to external events. Second, the mid-1950s initiates a period of much reduced variability, so much so that a different "regime" is suggested.

Figure $2 b$ is a similar graph for real defense outlays. Eight extreme values occur and they are all associated with wars (either buildups or demobilizations). Defense expenditures also experience a damping down of volatility after the mid-1950s, indicating that we are observing a general phenomenon.

Another way to examine these Noah effects is to aggregate the deviations in a frequency distribution and, more systematically, by plotting the frequencies versus the category (bin) midpoints on logarithmic scales. Figure 3a is such a frequency distribution, with the category midpoints for the "bins" for the distribution on the $x$-axis and the frequencies (here, years) in each bin on the $y$-axis. The extreme values that show up so clearly on the time series graph of Figure 2a here are the tails of the distribution. Clearly, this distribution is far from the Gaussian normal curve. The "best fit" Gaussian curve is superimposed on the frequency distribution and it is clear that the tails of the actual budgetary distribution far exceed those incorporated within the confines of the normal curve. 

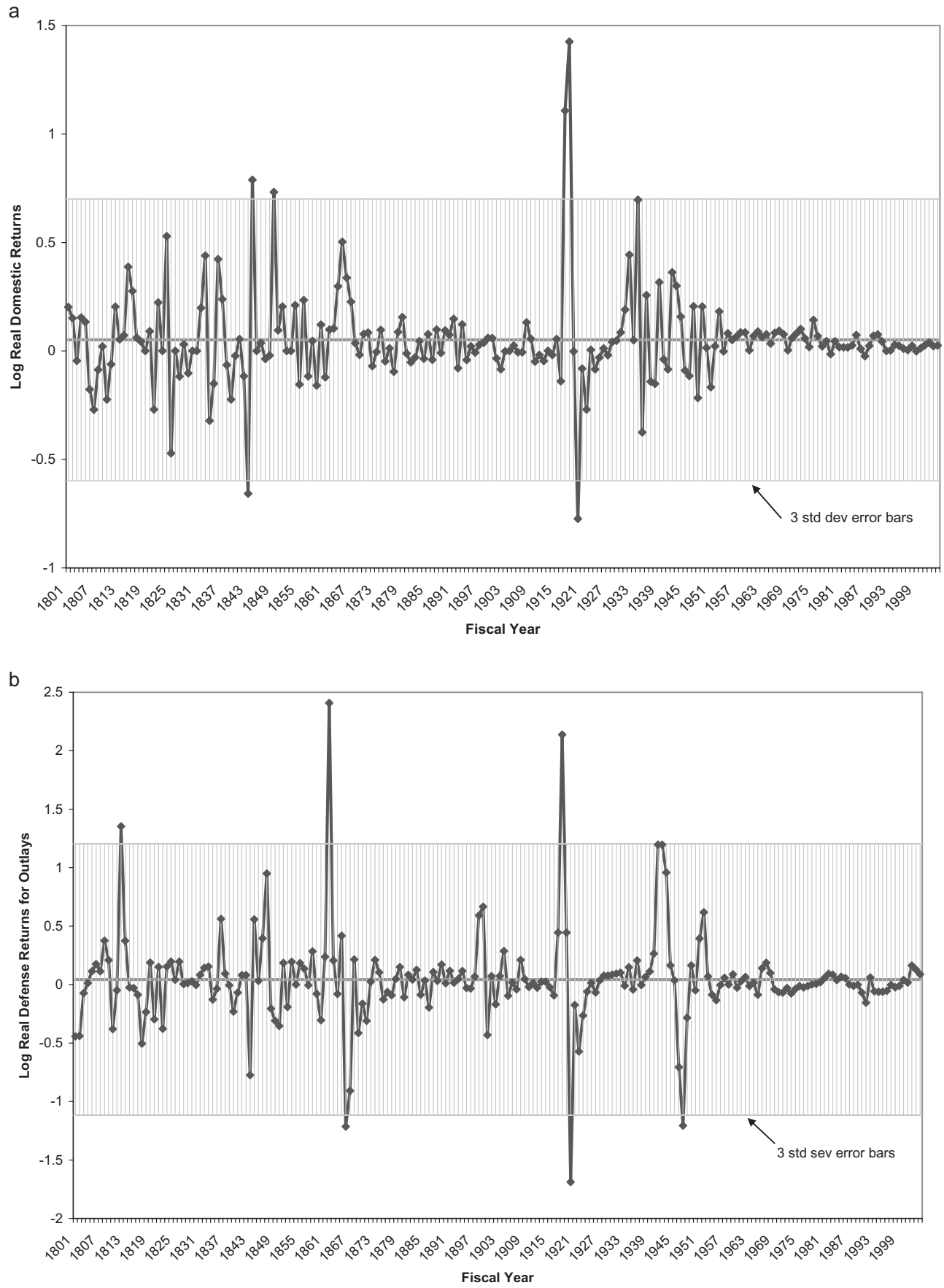

Figure 2. Real Annual Returns for U.S. Budgetary Outlays, 1800-2004: (a) Domestic Programs, (b) Defense. 


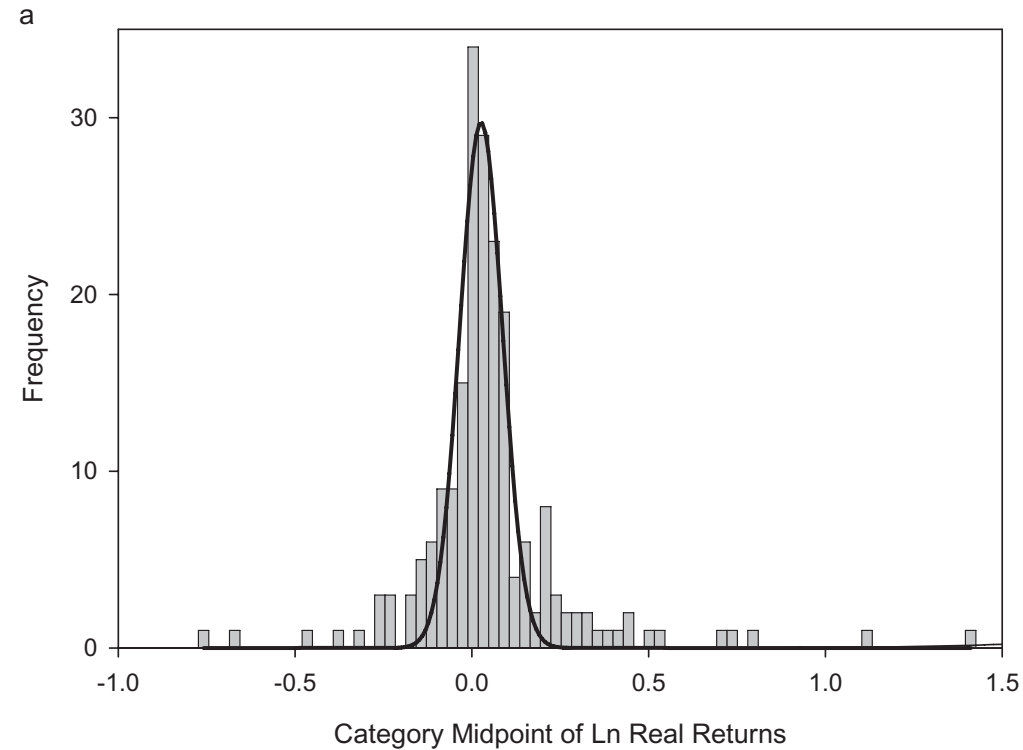

b

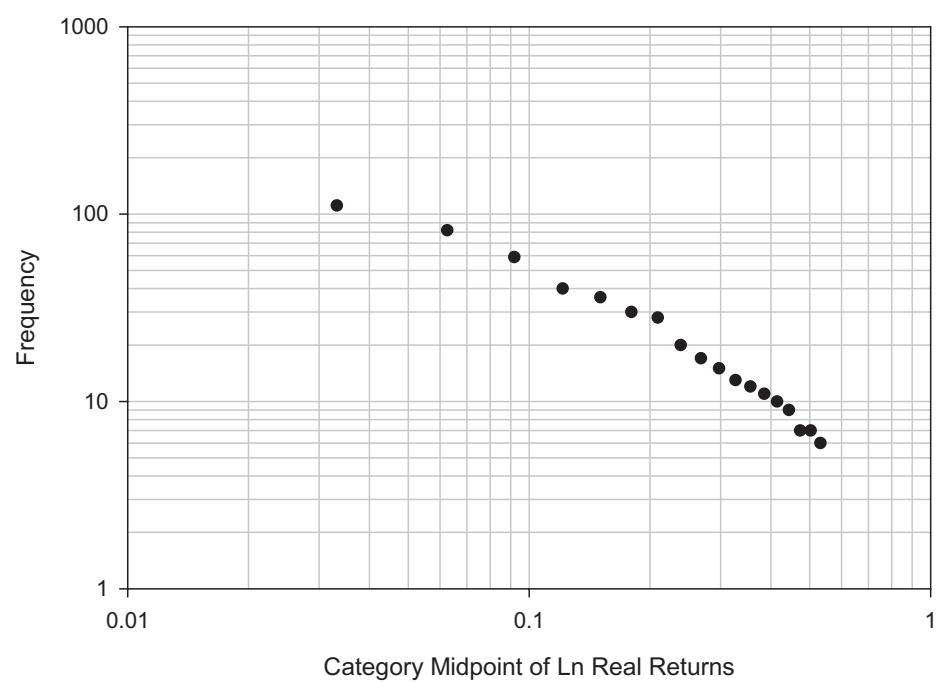

Figure 3. Real Annual Returns for Domestic Outlays, 1800-2004: (a) Frequency Distribution, (b) Log-Log Plot.

We can examine the distribution more systematically by producing a plot of the frequencies versus the category bin midpoints. If we take the logarithms of both sides of the plot and the plot approximates a straight line, then the underlying distribution is Paretian, or a power function. If the line is approximately straight in a log-linear plot, then the distribution is exponential. Both of these distributions indicate nonincremental budgetary processes (Jones \& Baumgartner, 2005b). The Paretian distribution is both fatter tailed and has a higher central peak than the Gaussian; the exponential has less fat tails but has high, slender peak. In fact, 
the distribution of returns for U.S. domestic outlays is approximately Paretian, as indicated in Figure $3 b .^{5}$ A more thorough study of many different budgetary distributions indicates that they are uniformly Paretian—very fat tailed, indicating "far from incremental" distributions (Jones et al., 2006).

Rare but extreme events disproportionately affect the long-term behavior of complex systems (Sornette, 2006, pp. 18, 396). For example, the large changes associated with World War I for real domestic expenditures (two large increases; one large reduction) resulted in a major long-term increase that was sustained until new major initiatives during the New Deal. As Figure 1 shows, the cutbacks did not offset the increases, resulting in a punctuation upward of total federal involvement in domestic affairs. Between 1916 and 1919, the federal budget for domestic affairs increased 12-fold, and even after several years of reductions settled down at a level more than three times the 1916 budget. $^{6}$

\section{Detecting Joseph Effects}

Figure 1 also indicates Mandelbrot's Joseph effects, the near-cycles that never actually repeat and have reverberations into current affairs. During and right after the Civil War, between 1863 and 1867, the federal budget for domestic programs quadrupled. Large increase was built on top of large increase, resulting in massive new spending for pensions and care for veterans and widows, as well as for new infrastructure and public work projects. This punctuation reached equilibrium, with spending drifting upward until World War I. From 1878 to 1916, the real federal domestic budget barely doubled.

Examining in more detail the period since the mid-1950s clearly shows the existence of "runs" of similar values for domestic expenditures. Figure 4 provides evidence. Such figure shows that the period between 1958 and 1976 was characterized by a period of robust growth in domestic budgets - of these 19 years, 15 were characterized by returns that were above the long-run average (the average for 1801-2004). Then, during the subsequent 28 years, only three were. ${ }^{7}$

One might be tempted to try to formulate a cyclical theory of budget change, but that would almost certainly be a mistake. A pattern of large changes and linked smaller ones is nevertheless random in the sense that it is a fool's errand to try to predict these outbreaks. Joseph effects are not regular cycles.

In combination, the Noah effects of rare but very large expenditure increases and the Joseph effects of linked budget increases account for most of the changes in federal domestic spending between the Civil War and World War II. This is the case even though most budget changes are "incremental" - minor adjustments from the previous year. The behavior of the series is indeed governed by its extreme values. If we can assess the structure of this long-term memory, we have nailed down empirically one important aspect of path dependence.

There are several ways to detect and measure long-term memory in time series. ${ }^{8}$ Memory in a time series means that a regression equation using the series would have correlated errors or disturbances. That is, two temporally adjacent observations would be correlated and this causes standard errors for the regression parameters to 


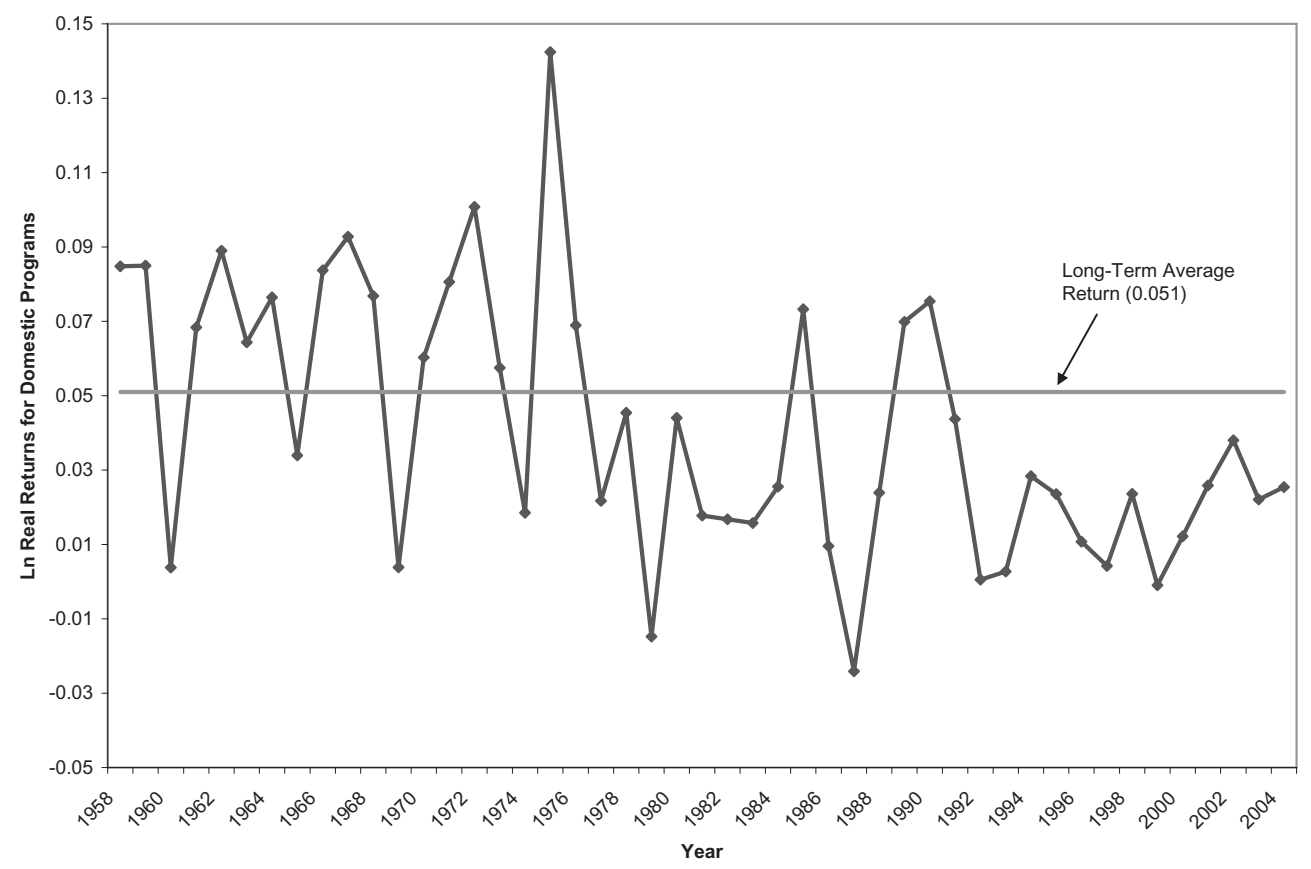

Figure 4. Real Annual Returns for Domestic Programs since 1957.

be underestimated. Analysts estimate the error structure directly and adjust for the problem. The cure depends on the nature of the error structure; in some cases (called first-order autoregression), the differences between observations are used; in more complex cases, analysts use different statistical estimators from the standard ordinary least squares approach.

Mandelbrot (1997) and Mandelbrot and Hudson (2004) realized that long-term memory was not just a complication for analysis, but it was also very meaningful in itself. It is the way past events continue to reverberate into the present. And, once realizing this, Mandelbrot saw that it is possible to compare the relative impacts of contemporaneous events with past ones.

The most direct way to assess the long-term memory of a time series is to examine the autocorrelation and partial autocorrelation functions. The autocorrelation function is the correlation between the values of the series and the values of the series lagged one time period, and then two periods, and so forth. The autocorrelation function is the set of correlations across the lags-one correlation for lag 1 versus lag 0 , one for lag 2 versus lag 0 , and so on. We generally plot the correlations against the number of lags. The correlation generally declines as the series "forgets" the past in the face of contemporary causes.

The partial autocorrelation function is the partial correlation between the series at lag 0 and the series at lag $k$, controlling for the lags between them. This tells us whether the memory is being carried directly from the past to the present (in which case, the partial autocorrelation coefficient would be significant) or whether the past affects the 

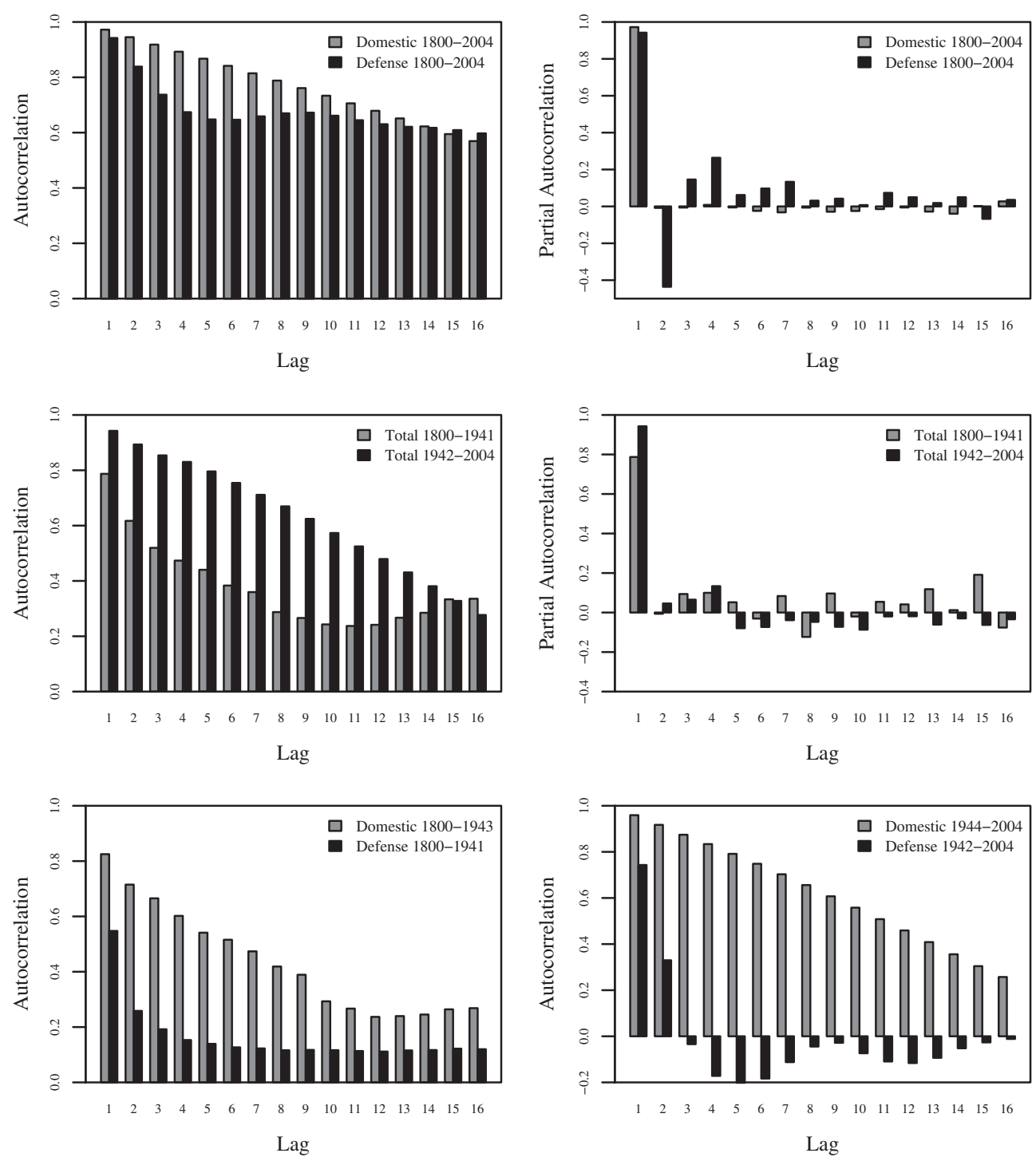

Figure 5. Autocorrelation and Partial Autocorrelation Functions. Notes: The first row shows the autocorrelation functions (ACFs) and partial autocorrelation functions (PACFs) for domestic and defense outlays 1800-2004. The second row includes the ACFs and PACFs for overall outlays for 1800-1941 and 1942-2004. The bottom row shows the ACFs for domestic and defense outlays for the pre and post-World War II eras.

present only through the intervening values of the series (indicated by an insignificant coefficient). Again, we plot the partial autocorrelation versus the number of lags.

Figure 5, the first plot on the first row, graphs the autocorrelation functions for U.S. domestic and defense outlays for the full period 1800-2004. The plots indicate excruciatingly long declines in the autocorrelations for both series; even after 20 years, the autocorrelations have only declined to 0.5 for domestic programs and 0.55 for defense. For defense, however, the correlation drops rapidly after the first 
Table 1. Outlays Series and Unit Root Tests

\begin{tabular}{lcccc}
\hline Outlays & \multicolumn{2}{c}{ KPSS Statistic } & \multicolumn{2}{c}{ Phillips-Perron's Z } \\
\hline & Constant & Trend & Constant & Trend \\
Total & $1.024^{* *}$ & $0.335^{* *}$ & 4.201 & 1.968 \\
Domestic & $0.927^{* *}$ & $0.311^{* *}$ & 5.072 & 3.4282 \\
Defense & $1.121^{* *}$ & $0.282^{* *}$ & $-0.921^{* *}$ & $-7.1088^{* *}$ \\
\hline Critical values: & $* *<0.01$. & & &
\end{tabular}

lag, indicating the effects of mobilization and demobilization, but it then stabilizes and gives every indication of lasting "forever." It seems that the system "remembers" every war. For domestic programs, however, the decline is linear, and at some point in the future, the system "forgets" past events.

Partial autocorrelation functions, depicted in Figure 5, second plot on the first row, sharply distinguish the two series. For domestic programs, the function declines to 0 after the first lag and never recovers. This is the classic signature of a first-order autoregressive process in which all memory of the past is carried through the previous year's budget. The system remembers the past, but only by looking back at last year. If this year's budget is some adjustment from the past (incremental or not), this pattern would emerge.

For defense, however, the partial autocorrelation for the first lag is positive, the second is close to 0 , and the third lag is strongly negative. This indicates a complex pattern; if the defense budget increases in one year, it will increase the next year (through "remembering") but will fall in the year after. Presumably again, this represents the effects of the process of mobilizing and demobilizing for war. Then the function becomes positive again before declining over time. This is a far more complex pattern and indicates that the transmission of the past is not a simple process of flowing through last year's budgets. Wars are remembered in budgets long past their immediate effects; demobilization is not complete.

Two common statistical tests can be employed to test for the degree of autocorrelation (or stationarity) in the total, domestic, and defense expenditure series. The first test is the KPSS unit root test where the null hypothesis is that stationarity prevails. For the Phillips-Perron unit root test, the null hypothesis is that a series has a unit root. We assume that the deterministic component is a constant without and with linear trend as well as long-term memory (i.e., a long lag structure; for alternative setups, the results are even stronger). Based on Table 1, we can reject the hypothesis that the three series-total, domestic, and defense-are level or trend stationary. However, there is some evidence based on the Philips-Perron test that the defense expenditures might be stationary. Overall, the three series suggest that time trends matter greatly and need careful consideration. Long-term memory matters.

\section{Budgetary Regimes}

It is possible that the memory structure in budgets can be altered through clear breaks from the past, essentially dividing the series into separate budgetary regimes. More generally, can we reconstruct budgetary regimes from the historical traces 
of budget data that suggest different decision-making mechanisms underlie the different regimes?

In order to examine whether there are distinct budgetary regimes prevalent in the data, we identify structural changes in the three series-total outlays, domestic spending, and defense spending. The Bayesian Information Criterion (BIC) and the Residual Sum of Squares (RSS) can be employed for identifying the optimal number of break points (Bai \& Perron, 2003). Both are tools for model selection (in our case to find a model with the "ideal" number of break points). The "best" model is selected by finding the minimum of the RSS or BIC, given the hypothesized break points. The initial assumption is that the series are linear. For the spending series, Figure 6 identifies the number and location of break points in the series. The time series plot display the time series (black line), the structural break points (dashed vertical line), and the coefficients for the resulting budgetary regimes (gray line).

There is strong evidence for a structural break during World War II in all three series. For the overall series, there seems to be a second break in the mid-1970s. For the overall outlays, we are 95 percent confident that there is a break in 1941 and a second break between 1973 and 1975. The final partition suggests three regimes dating from 1800 to 1941,1942 to 1974 , and 1975 to 2004 . $^{9}$ Similarly, for the domestic outlays, we are 95 percent confident that there is a structural break in 1943 and another between 1973 and 1975, and therefore, we can partition the domestic outlays series into three regimes: 1800-1943, 1944-1974, and 1975-2004. Finally, the defense outlays display one structural break in 1941. In contrast to the other two series, there is not much evidence for an additional regime break in the mid-1970s.

The break in budgetary behavior in the mid-1970s is almost certainly associated with the Congressional Budget and Impoundment Control Act of 1974. This act instituted a regularized budget procedure for Congress that matched the wellestablished executive branch procedures by establishing budget committees and the Congressional Budget Office.

Our data suggest that World War II initiated a budgetary "regime change" with different memory patterns before and after the break. Figure 5 (rows 2 and 3) shows a real difference in the patterning of the autocorrelation functions in two time periods, before and after World War II. In the earlier period, memory drops off as lags increase, but some residual effects go on basically infinitely (at least until the WWII break).

Compare this to the latter, postwar period. There memory declines linearly in a well-behaved pattern, but quite slowly. Even after 15 years, the autocorrelation is still a statistically significant .30. Moreover, as Figure 5 (row 2) shows, most of the memory is carried though the previous year in the classic AR1 process. Whatever contemporaneous events affect the budget are incorporated into the process annually and are carried forward for many, many years until finally current events wash out the older effects. This is well-behaved budgeting, but it is not incremental budgeting (otherwise there could be no Noah effects).

Figure 5, row 3, plots the autocorrelation function (ACF) for the period from 1800 through World War II separately for domestic and defense outlays. The process of mobilization and demobilization that occurred throughout most of American history results in a defense series with little long-term memory. The defense budget 

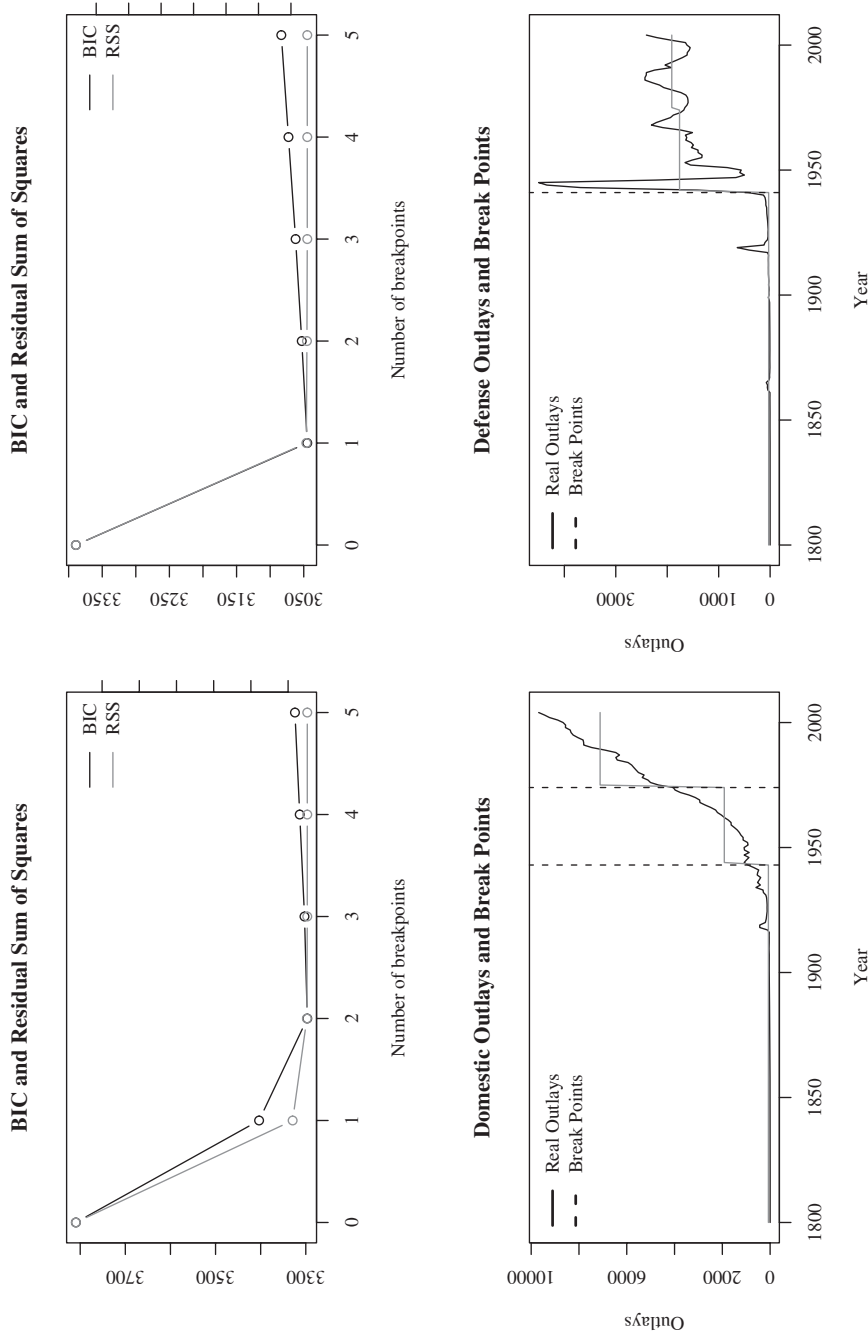

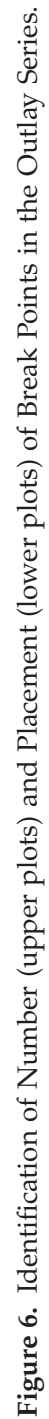
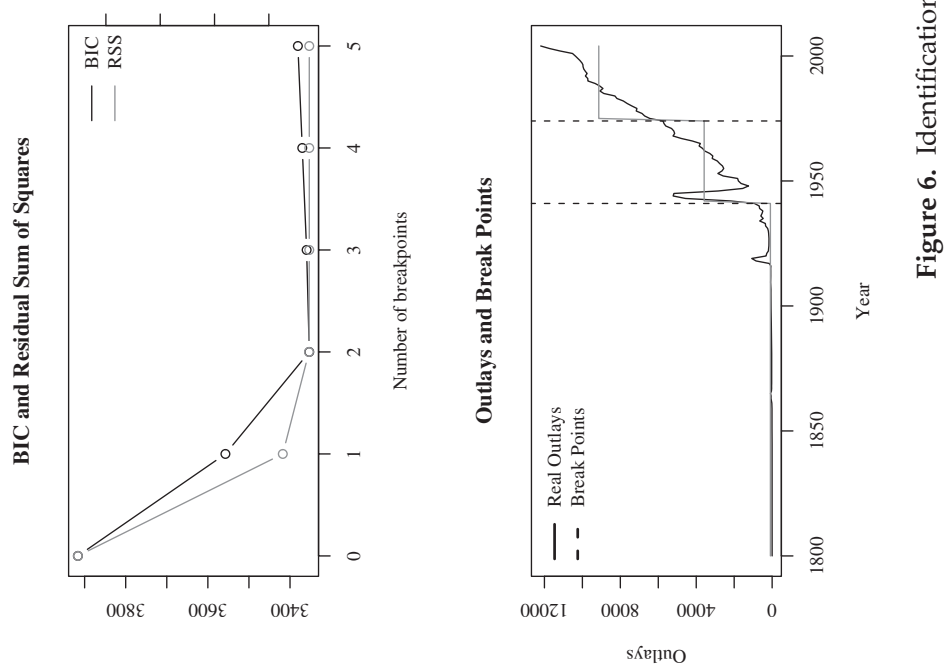
in any one year is essentially uncorrelated with expenditures four years previously (or later). Budgeting was de novo for each war. However, for domestic programs, the situation is quite different. While memory declines, it does not extinguish. Even after 20 years, past expenditures continue to affect the present. The postwar period examined separately in Figure 5, row 3, shows the expected stability, but defense budgeting does experience more rapid decline in autocorrelations than domestic spending.

The best way to characterize the Joseph effects in U.S. outlays is that World War II and the subsequent transformation of American politics acted as a divide through which little memory was transmitted. That of course does not mean that people did not remember or that policy was not affected by the past; it means that in budget series, two separate periods are clearly distinguishable. One, the earlier period, is characterized by extremely large, but rare, events that shook the foundations of the nation, and which affected how the defense of the nation was funded over the long term. The series "forgot" much but not the entire disruptive event as the nation demobilized; some was "remembered" as indicated by the leveling off of the ACF in Figure 5, row 3. In the second period, there continue to be defense mobilizations and demobilizations, but despite that, the defense establishment never closes down the way it did in the past. However, these events did continue to reverberate through domestic programs; while armies demobilized, the domestic state grew (Sparrow, 1996).$^{10}$

One final observation: the period from the Civil War to World War I looks quite similar to the modern post-World War II period. A similar large-scale disruption, making the whole series look more like it did in the past, is clearly not impossible-one can never rule out Noah effects, even when budgets and economies are better managed.

\section{Modern Programmatic Evidence}

The stories of Noah and Joseph are not over in the modern era; we have not banished them to the dustbin of history. While economic and political management have stabilized the rough-and-tumble budgeting of the past, there are still plenty of instances of rapid program buildup and continued influence over several years. Indeed, aggregating across all Office of Management and Budget functional categories yields the signature power function that signals Mandelbrot's Noah effects (Jones et al., 2006).

Figure 7 plots Congressional Budget Authority for Crime and Justice. ${ }^{11}$ We can see clear evidence of extreme events ( 4 of the 56 observations, or 7 percent, exceed three standard deviations from the average, whereas based on Gaussian statistics, we expect to find less than one case of such an extreme value)..$^{12}$ Indeed, were budgets to be distributed normally, we would expect to find a value beyond three standard deviations in either direction to occur only once every 373 years.

Just as clear is evidence of Joseph effects. All of the six years after 1968 have returns of greater than average. If we treat the probabilities of falling above or below the average as equally likely (as they will be in Gaussian distributions), the probability of this happening is about 1.5 percent. In the 1990s, six out of eight years running include budgets for crime and justice above average. ${ }^{13}$ 

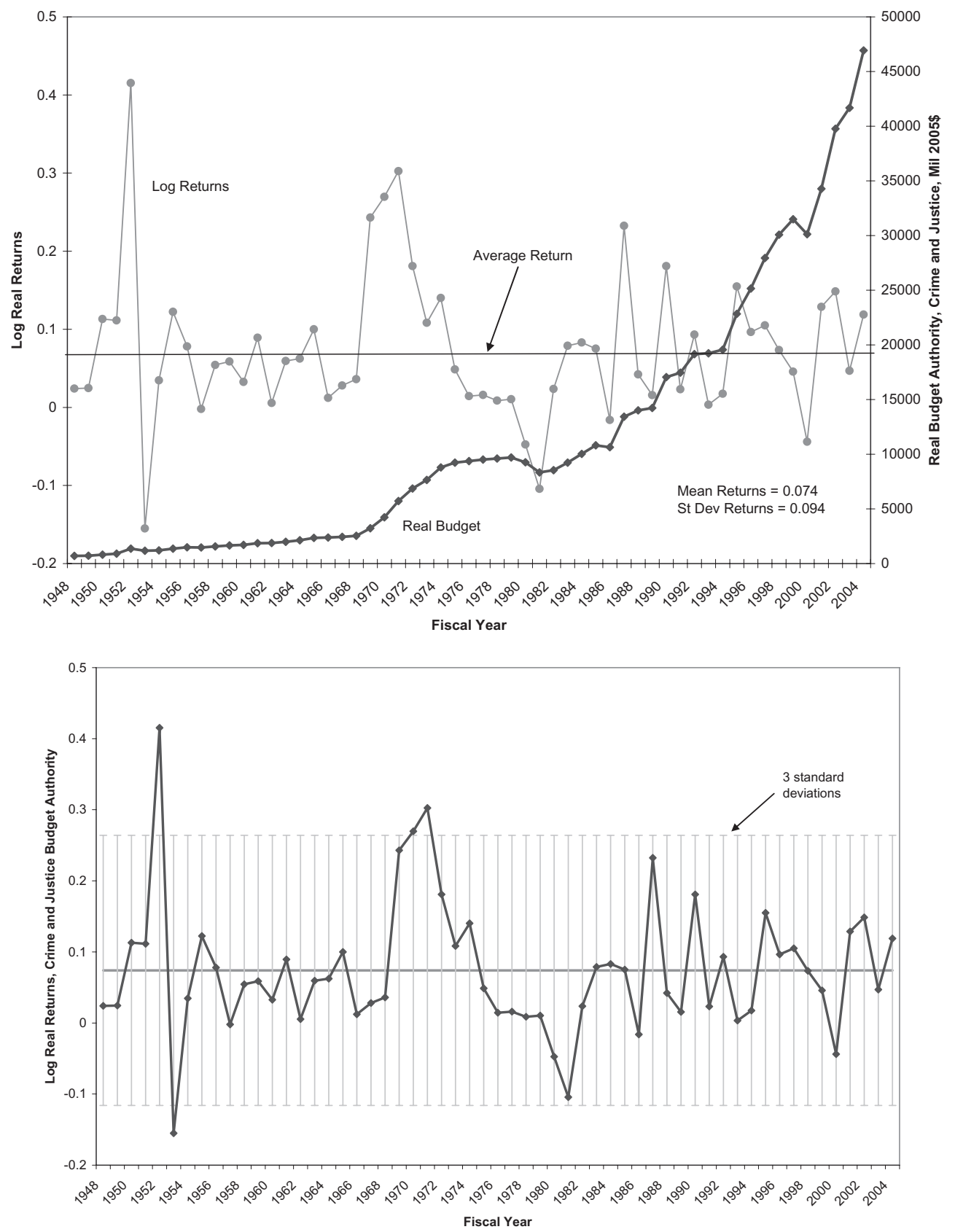

Figure 7. U.S. Budget Authority for Crime and Justice: (a) Log Returns and Budget Authority; (b) Log Returns with Error Bars.

Are Public Budgets Nonequilibrium Systems?

Let us examine one final issue at this point. Evolving complex systems are generally not at equilibrium — they do not return to some steady state when disturbed. 
Moreover, some out-of-equilibrium systems are capable of reaching "critical states" in which large-scale changes are much more likely to occur, with long-range effects on the behavior of the entire system through time. In contrast, equilibrium systems rapidly return to the status quo ante and immediately "forget" the disruption.

We know that U.S. expenditures are characterized by non-Gaussian processes and that the long-term behavior of budgets is heavily influenced by large but rare events (the punctuations of the Noah effect). Furthermore, we find runs of similar values that are adjacent in time and these runs are reflected in the graphs that plot these autocorrelations against the number of lags. Both are indicative of Joseph effects of time series that "remember." Such systems are candidates for "selforganized criticality" or SOC (Bak, 1997). The idea is that systems can move into a state that causes them to be "poised" between stability resembling equilibrium and huge, cascading changes. Fluctuations can push a previously stable system into the critical region, resulting in such changes.

In public budgets, there are several processes that lead to such behaviors-in particular "bidding wars" in which the two political parties rush to spend on a program to "prove" their fealty to the objective. This happened in the 1980s regarding crime control and mandatory sentencing in the wake of the crack cocaine alleged epidemic, and these effects show up in the budget series presented in Figure 7. This sort of "urgency" generally destabilizes the previous policy understanding.

The SOC description may include several different causal mechanisms, but there seem to be two characteristics of such systems in general (Sornette, 2006, p. 396). These are our familiar Noah and Joseph effects: large punctuations and long-term memory. Specifically, the frequency distribution of changes should follow a power law and the long-range decay of autocorrelations should also follow a power law. We have seen that the first condition is met in public budgets (see Jones et al., 2006). A power law for autocorrelations implies that memory is infinite; all events continue to influence the present, even if in weakened form. This leads to overly sensitive systems subject to destabilization.

The condition that autocorrelations follow a power function is met for budgets before and after World War II, for both domestic and defense expenditures. ${ }^{14}$ Such a system is potentially subject to destabilization with wide ramifications for the longrange behavior of the system.

We can substantiate the idea of the long-range behavior of the system by detecting the long-term memory effects in these outlays series via the computation of the Hurst exponent (Ding, Granger, \& Engle, 1993; Hurst, 1951). The Hurst exponent is based on the relationship between the autocorrelation function and its accompanying lag structure. This relationship can be summarized by a linear regression fit of the $\log -\log$ plot for the autocorrelation function. From the slope of this regression, the Hurst exponent is derived.

A Joseph effect is quantified by the Hurst exponent, where movements fall between a Hurst range of 0 to 0.5 . If the measure is 0.5 , then the movements are thought to be random movements. If it is between 0.5 and 1 , the movements are thought to be part of a long-term trend, and therefore, identify Noah effects. Table 2 shows the Hurst exponents for the three expenditure series. All three of them display 
Table 2. Hurst Exponents for Detection of Long-Term Memory in the Three Outlays Series, 1800-2004

\begin{tabular}{lccc}
\hline Statistic & Outlays & Domestic & Defense \\
\hline Maximum lag & 23 & 23 & 23 \\
Cut-off conference level & 0.136 & 0.136 & 0.136 \\
Plot-intercept & 0.175 & 0.239 & -0.082 \\
Plot-slope & -0.236 & -0.292 & -0.169 \\
Hurst exponent & 0.882 & 0.854 & 0.915 \\
\hline
\end{tabular}

strong long-term memory trends. These long-term memory trends also hold for different partitions of the series (e.g., pre- and post-WWII, by century, and by structural breaks).

\section{Conclusions}

Clear evidence of both large-scale but rare punctuations and long-term memory can be found in U.S. budgetary series. For the whole budget, these effects are strong prior to World War II, but much weaker afterward. For individual programs, however, both effects are clearly detectable, as our example of crime and justice programs indicated.

The findings of extreme values and long-term effects are not consistent with the traditional incrementalist view of budgeting, which requires a Gaussian distribution of first differences and, consequently, of associated measures such as percentage change and returns (Jones \& Baumgartner, 2005a, 2005b; Padgett, 1980, 1981). Yet ironically, the past effects of expenditures are carried in the previous year's budget-since World War II, but not before. Modern budgeting, then, is characterized by an adjustment from last year's budget and these adjustments are incorporated the next year into the budget base, just as the incrementalists claimed (Davis, Dempster, \& Wildavsky, 1966, 1974; Wildavsky, 1964). However, the adjustment process is oftentimes not at all incremental. One might characterize budgeting since World War II as nonincremental but well behaved.

Before World War II, budgeting was neither incremental nor well behaved because punctuations were even more severe and memory was not characterized by simple autoregressive properties. The obvious break that occurred after the World War II probably signaled a regime shift in how policy was made in America, but even the more stable modern world is far more uncertain than the traditional incremental view.

It is clear that the term "path dependence" has lots of meanings, even when we constrain the term to long-term memory. However, the procedures for studying long-term memory are well established and can serve as a benchmark for examining how history matters. The study of memory in budgetary time series offers an important way to think about path dependence and the role of history in public policy processes.

Bryan D. Jones is Donald R. Matthews Distinguished Professor of American Politics and Director of the Center for American Politics and Public Policy at the University of Washington. 
Christian Breunig received a PhD from the University of Washington and is a post-doctoral fellow at the Max Planck Institute for the Study of Societies. In 2008, he will join the University of Toronto.

\section{Notes}

1. U.S. Government Outlays are from Historical Statistics of the United States, compiled by the U.S. Census Bureau, updated from the Office of Management and Budget website, Historical Statistics, table 1.1. The Consumer Price Index was used to adjust for inflation attributed to the absence of GDP deflators for the early part of the series, with June $1984=100$. These outlay data are the workhorse for historical analyses of the federal budget (Schick, 2000).

2. One possible issue with this analysis is variability in data quality over the series that could account for some of the differences we detect. Note that we study outlays here, not budget authority; the former is a better measure for assessing decision making but the latter, a simple tabulation across the government's accounts, is a simpler measure that is consistent across the time period studied. There was no public budget, strictly speaking, before the executive branch started preparing one after the Budget and Accounting Act of 1921, and no true congressional budget until after the Congressional Budget and Impoundment Control Act of 1974. Nevertheless, at the gross levels of reporting (defense versus domestic), errors are less likely than in more exacting data. Finally, many (but not all) of the effects we report here are inconsistent with shifts in outlays data quality, which was excellent after the founding of the Bureau of the Budget in 1921.

3. Return on an investment is just the current value of the investment divided by its value at the last time period. Logarithmic returns, the natural logarithm of the returns, basically assume that the asset is continuously compounded, which assumes that whatever forces are operating on budgetary affairs operates in a continuously compounding manner. This may or may not be a sound assumption for studying budgets. In any case, using the more standard percentage change measure yields generally similar results, but percentage changes overweight any change from a low value. Logarithmic returns avoid this problem. For example, a budgetary change from $\$ 10$ million to $\$ 100$ million is $(100-10)$ / $10 \times 100=900$ percent. For the logarithmic return, $\ln (100 / 10)=\ln (10)=2.3$ (because natural $\operatorname{logs}$ are used).

4. Using the standard deviation as a benchmark underestimates the existence of extreme values, as it is sensitive to these extremes, because it is the square root of mean squared deviations, and squaring a large deviation will cause the measure to grow rapidly. Indeed, for power functions (which characterize budget distributions), the standard deviation is infinite (but of course it can always be calculated on a finite sample of observations).

5. Estimating the probability distribution underlying an observed frequency distribution can be tricky in practice, and several different distributions yield similar enough plots that they can be confused (Sornette, 2006).

6. Remember that the log-linear plot causes ratios to be equal (on the $y$-axis), not the actual numbers.

7. See Jones, Baumgartner, and True (1998) for a different method of isolating these "budgetary eras."

8. Nelson and Plosser (1982) started a long-standing discussion about the trends in many macroeconomic time series.

9. This pattern is not consistent with any alternate hypotheses concerning changes in data quality.

10. Sparrow's (1996) superb study of the building of government after WWII shows how this happened in one major case. Sparrow also offers evidence that is generally supportive of the "break point" interpretation of WWII offered here.

11. U.S. Budget Authority data are derived from Office of Management and Budget Sources, which adjust categories for consistency after 1976. The Policy Agendas Project (http://www.policyagendas.org) applied consistent adjustments back to 1947. Data are adjusted for inflation using GDP deflators, with 2005 as the base year.

12. The normal or Gaussian curve at three standard deviations includes 99.7 percent of the observations, with only three one-hundredths of a percent ( 0.003 percent) falling outside. 
13. The autocorrelation function displays very long-term linear decline and an AR1 process, the general pattern since WWII.

14. Power functions decay rapidly at first, but then stabilize and never reach 0 . Exponential functions decay slightly less rapidly, but damp out. Linear ACFs also damp out, but they may do so at an excruciating rate if the slope is shallow enough. For defense, the ACF declines to insignificance after a few lags, while displaying a power function. The ACF for domestic expenditures, however, reaches an asymptote at around 0.17 and is still statistically significant at 20 lags. For domestic expenditures, $\mathrm{ACF}=0.115-0.637 L ; r^{2}=0.896$; for defense, $\mathrm{ACF}=0.190-2.179 L ; r^{2}=0.967 ; L$ is the number of lags. The steeper slope for defense indicates a more rapid decline of memory.

\section{References}

Arthur, W. Brian. 1994. Increasing Returns and Path Dependence in the Economy. Ann Arbor, MI: University of Michigan Press.

Bai, Jushan Bai, and Pierre Perron. 2003. "Computation and Analysis of Multiple Structural Change Models." Journal of Applied Econometric 18: 1-22.

Bak, Per. 1997. How Nature Works. New York: Springer-Verlag.

Baumgartner, Frank R., and Bryan D. Jones. 1993. Agendas and Instability in American Politics. Chicago: University of Chicago Press.

Beinhocker, Eric D. 2006. The Origin of Wealth. Boston: Harvard Business School Press.

Campbell, John, Andrew Lo, and A. Craig MacKinlay. 1997. The Econometrics of Financial Markets. Princeton, NJ: Princeton University Press.

Cootner, Paul. 1964. The Random Character of Stock Market Prices. Cambridge, MA: The MIT Press.

Davis, Otto A., M. A. H. Dempster, and Aaron Wildavsky. 1966. "A Theory of the Budget Process." American Political Science Review 60: 529-47.

—. 1974. "Towards a Predictive Theory of Government Expenditure: US Domestic Appropriations." British Journal of Political Science 4: 419-52.

Ding, Zhuanxin, Clive W. J. Granger, and Robert F. Engle. 1993. “A Long Memory Property of Stock Returns and a New Model." Journal of Empirical Finance 1: 83-106.

Hurst, Harold E. 1951. "Long Term Storage Capacity of Reservoirs." Transactions of the American Society of Civil Engineers 116: 770-99.

Jones, Bryan D., and Frank R. Baumgartner. 2005a. The Politics of Attention. Chicago: University of Chicago Press.

- 2005b. "A Model of Choice for Public Policy." Journal of Public Administration Theory 15: 325-51.

Jones, Bryan D., Frank R. Baumgartner, Christian Breunig, James A. Stimson, Martial Foucault, Abel François, Christoffer Green-Pedersen, Peter John, Chris Koske, Peter B. Mortensen, Scott Robinson, Stuart Soroka, Frédéric Varone, Stefaan Walgrave, and Chris Wlezien. 2006. "Are Political Systems Poised between the 'Order' of Friction and the 'Chaos' of Urgency? Public Budgeting in Comparative Perspective." Working Paper, Center for American Politics and Public Policy, University of Washington.

Jones, Bryan D., Frank R. Baumgartner, and James L. True. 1998. “Policy Punctuations: US Budget Authority, 1947-95." Journal of Politics 60: 1-30.

Kotz, Samuel, and Saraless Nadarajah. 2000. Extreme Value Distributions. London: Imperial College Press.

Levi, Margaret. 1997. "A Model, Method, and Map: Rational Choice In Comparative and Historical Analysis." In Comparative Politics: Rationality, Culture, and Structure, ed. Mark Lichbach and Alan Zucherman. Cambridge: Cambridge University Press, 19-41.

Malevergne, Yannick, and Didier Sornette. 2006. Extreme Financial Risks. New York: Springer.

Mandelbrot, Benoit. 1967. "The Variation of Some Other Speculative Prices." Journal of Business 40: 393-214. 1997. Fractals and Scaling in Finance. New York: Springer.

Mandelbrot, Benoit, and Richard L. Hudson. 2004. The (Mis)Behavior of Markets. New York: Basic Books. 
Mantegna, Rosario N., and H. Eugene Stanley. 2000. An Introduction to Econophysics. Cambridge: Cambridge University Press.

Mirowski, Philip. 1990. "From Mandelbrot to Chaos in Economic Theory." Southern Economics Journal 57: 289-307.

Nelson, C. R., and C. I. Plosser. 1982. "Trends and Random Walks In Macroeconomic Time Series: Some Evidence and Implications." Journal of Monetary Economics 10: 139-62.

Padgett, John F. 1980. "Bounded Rationality in Budgetary Research." American Political Science Review 74: 354-72.

- 1981. "Hierarchy and Ecological Control in Federal Budgetary Decision Making." American Journal of Sociology 87: 75-128.

Page, Scott E. 2006. "Path Dependence." Quarterly Journal of Political Science 1: 87-115.

Pierson, Paul. 2004. Politics in Time. Princeton, NJ: Princeton University Press.

Richardson, Lewis F. 1960. The Statistics of Deadly Quarrels. Pacific Grove, CA: Boxwood Press.

Rose, Richard, and Philip Davies. 1994. Inheritance in Public Policy: Change without Choice in Britain. New Haven, CT: Yale University Press.

Schick, Allen. 2000. The Federal Budget: Politics, Policy, Process. Washington, DC: Brookings Institutions Press.

Sornette, Didier. 2003. Why Stock Markets Crash. Princeton, NJ: Princeton University Press.

- 2006. Critical Phenomena in Natural Sciences, 2nd ed. New York: Springer.

Sparrow, Bartholomew. 1996. From the Outside in. Princeton, NJ: Princeton University Press.

True, James, Bryan Jones, and Frank Baumgartner. 2007. "Punctuated Equilibrium Theory: Explaining Stability and Change in Policymaking." In Theories of the Policy Process, ed. Paul Sabbatier. Boulder, CO: Westview Press, 155-88.

Wildavsky, Aaron. 1964. The Politics of the Budgetary Process. Boston: Little, Brown.

\section{Appendix: Supplemental Analysis}

Table A.1 presents kurtosis and L-kurtosis scores for the full series and separately for before and after the WWII break. It indicates that all budgets are leptokurtic for all periods and that there is little difference in the magnitude of these punctuations. For totals and defense outlays, the post-WWII kurtosis is slightly higher. However, domestic budgets appear to be less punctuated in the post-WWII era. It seems that the break does not indicate any substantial shift in the relative size of punctuations, but it did shift the memory structure of the series.

Table A.1. Kurtosis Scores for Budget Series

\begin{tabular}{lcc}
\hline Series & L-kurtosis & Kurtosis \\
\hline Total & & \\
1800-2004 & 0.46 & 17.64 \\
1800-1945 & 0.41 & 13.94 \\
1946-2004 & 0.55 & 14.86 \\
Domestic & & \\
1800-2004 & 0.40 & 14.59 \\
1800-1945 & 0.35 & 10.81 \\
1946-2004 & 0.32 & 6.80 \\
Defense & & \\
1800-2004 & 0.45 & 15.39 \\
1800-1945 & 0.42 & 12.60 \\
$1946-2004$ & 0.49 & 17.21 \\
\hline
\end{tabular}

